\title{
Scad Geo Spatial Web Solution
}

\author{
Roshini $^{1}$ and Angelin Ranjithamani ${ }^{2}$ Deepa $^{3}$ \\ ${ }^{1}$ Department of Computer Application, Francis Xavier Engineering College. \\ ${ }^{2}$ HOD,Department of Computer Application, Francis Xavier Engineering \\ College.
}

${ }^{3}$ Department of Computer Application, Francis Xavier Engineering College.

\begin{abstract}
Local bodies like municipalities need collect different kind of taxes from the citizens. Every citizen need to pay Water Bills and Electricity Bills to the particular authorities. Actually a citizen want to pay his municipal tax means he should go to municipal office and collect the necessary bill, pay there only. Same as water and electricity bills. This is not an easy job to get all these tax information in different authorities now days. For that purpose we are developing this application, which can collect the tax information from different authorities based on the house no's and owner name by using web services and stores the data in our own database. For getting the information regarding taxes citizens need to register first. The bill are calculating on different modes like annual, half yearly, quarterly etc... By using the user id and password citizens can log into the system and collect the necessary information from the home page. For this every user need to provide his house no and owner name. By clicking on the search button they will get their own. The smart city is equipped with the electronic circuitry where the weight of the garbage in the bin is measured and the value is updated in the database. The database of the families will be created and maintained by the municipality. A web portal gives the involved people and authorities access to the related information. A house is penalized for every kilogram more than the allotted garbage weight limit. Further enhancements are explored. Thus, the residents are incentivized to produce lesser waste.
\end{abstract}

\section{KEYWORDS}

Payments, Tax and Bills

\section{INTRODUCTION}

Local bodies like municipalities need collect different kind of taxes from the citizens. Every citizen need to pay Water Bills and Electricity Bills to the particular authorities. Actually a citizen want to pay his municipal tax means he should go to municipal office and collect the necessary bill, pay there only. Same as water and electricity bills. This is not an easy job to get all these tax information in different authorities now days.

For that reason we are building up this application, which can gather the assessment data from various specialists in light of the house no's and proprietor name by utilizing Web Services and stores the information in our own database. Forgetting the data with respect to charges natives need to enroll first. The bill is ascertaining on various modes like yearly, half-yearly, quarterly and so on. 
By utilizing the client id and secret key nationals can sign into the framework and gather the important data from the landing page. Supply of drinking water, Providing and keeping up waste and sewage frameworks, Public road lighting, Maintaining sanitation and cleanliness of open spots, Providing Electricity Connection to national houses, Providing Water Connection to houses, Municipal Maintenance.

For that purpose we are developing this application, which can collect the tax information from different authorities based on the house no's and owner name by using web services and stores the data in our own database. For getting the information regarding taxes citizens need to register first. The bill are calculating on different modes like annual, half yearly, quarterly etc...

\section{Problem Statement}

The current framework is the manual framework. Here the representatives need to spare the data as exceed expectations sheets or Disk Drives. There is no sharing is conceivable if the information is as paper or Disk drives. Looking for specific data is exceptionally basic it requires the parcel of investment. Social occasion data from various sources isn't a simple occupation, information will be botched. Ascertaining distinctive bills physically going to be as a procedure of error. There is no interface to give different bills in the current framework. In the current framework native get the bill's data physically, in different specialists like water board, power office, property impose division and so on.

The improvement of this new framework contains the accompanying exercises, which endeavor to mechanize the whole procedure keeping in the perspective of database joining approach. There no weight of figuring water, electric, house impose charges in this framework, by sending a demand to the specific expert by means of web benefit we can get all the data with respect to these issues. The organization is the primary individual of this framework. He can have every one of the benefits to do anything in this framework. An administrator can get the data with respect to national's water charges, electric bills, and city charges from different sources. For that chairman need to send a demand for that specific specialist toss web administrations.

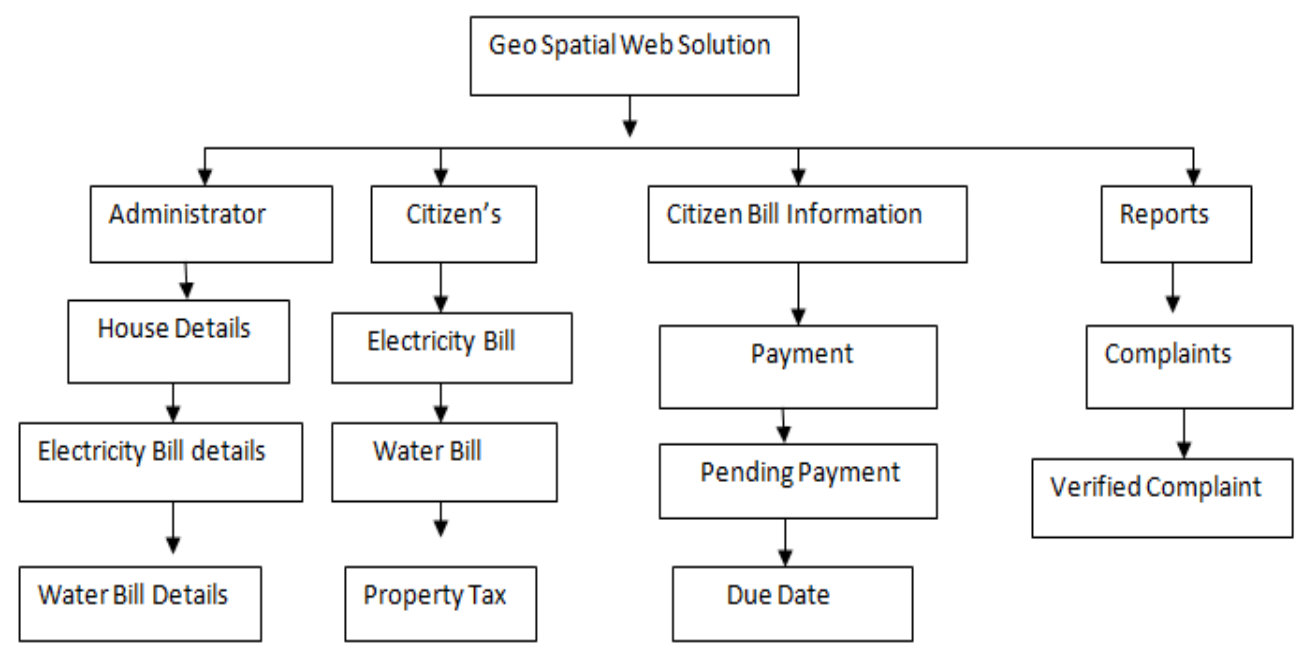

Figure: 1 Architecture Diagram 


\section{EXPERIMENT AND RESULTS}

\subsection{Administration}

Administration is the main person of this system. He can have all the privileges to do anything in this system. Admin can get the information regarding citizen's water bills, electric bills, and municipal taxes from various sources. For that administrator need to send a request for that particular authority throw web services.

\subsection{Citizen Bill Information}

The system interface is going to show the Bill information of different authorities. The bills mainly going to these types ,Water Bills , Electricity Bills , Property Taxes These interface also shows the, Pending Bills, Penalties, Due Dates.

\subsection{Search}

By using the user id and password citizens can log into the system and collect the necessary information from the home page. For this every user need to provide his house no and owner name. By clicking on the search button they will get their own.

* House Members Details

* Electricity Bill Details

* Water Bill Details

* Pending Bills

* Dues Dates

\subsection{Reports}

The problem can be reported in the pages. For Example,

* Supply of Drinking Water.

* Providing Water connection to houses.

* Sending water bills to houses.

* Public Street Lighting.

* Maintaining sanitation and hygiene of public places.

\subsection{Database Collections}

The administrative user interface concentrates on the consistent information that is practically, part of the organizational activities and which needs proper authentication for the data collection. The interfaces help the administrations with all the transactional states like Data insertion, Data deletion and Data updating along with the extensive data search capabilities.The operational or generic user interface helps the users upon the system in transactions through the existing data and required services. The operational user interface also helps the ordinary users in managing their own information helps the ordinary users in managing their own information in a customized manner as per the assisted flexibilities 


\subsection{About Project}

The major inputs and outputs and major functions of the system are follows:

Admin enter his user id and password for login. User enters his user id and password for login. Admin enter user id or date for track the user login information New users give his completed personnel, address and phone details for registration. Admin gives different kind of user information for search the user data. User gives his user id, hint question, answer for getting the forgotten password. User request for Municipal Bill. Admin can have his own home page.

Users enter their own home page. The user defined data can store in the centralized database. Admin will get the login information of a particular user. The new user's data will be stored in the centralized database. Admin get the search details of different criteria. User can get his forgot password. User can get the Bill Details.

\section{Output Screen}

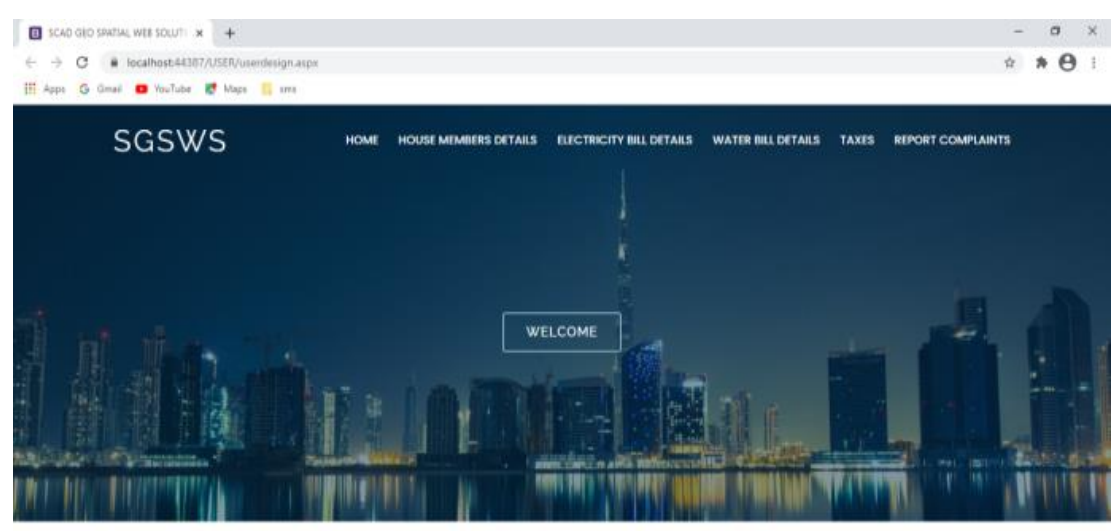

*

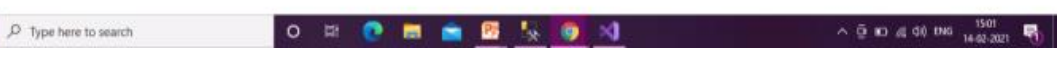

Figure: 1 Home Page

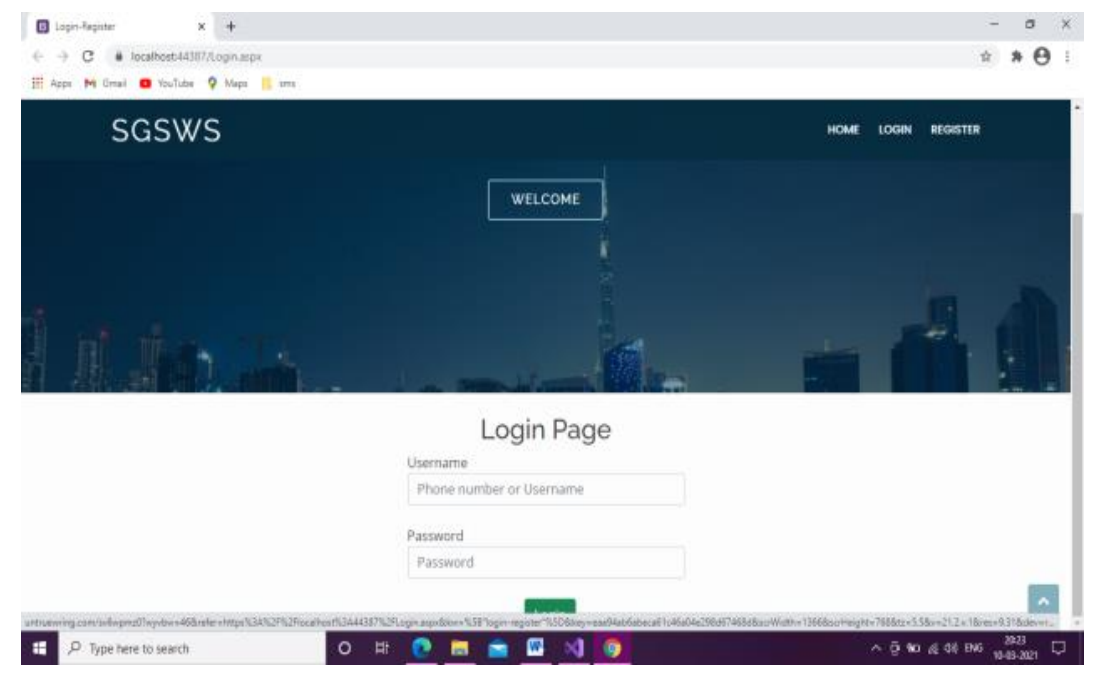

Figure: 2 Login Page 


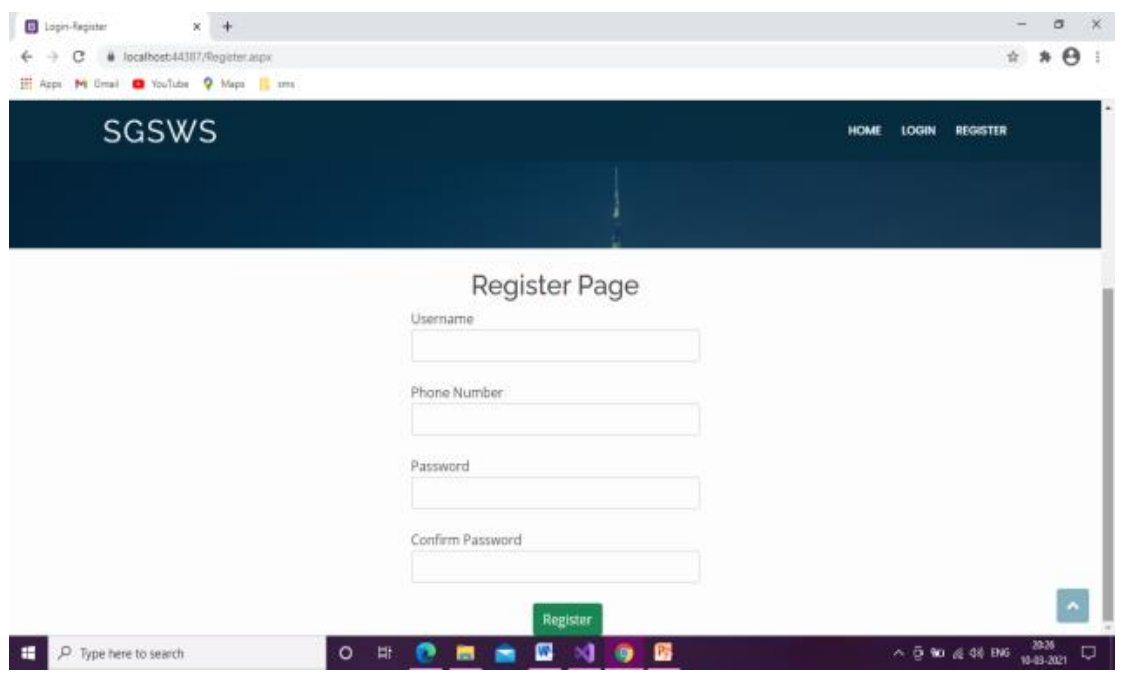

Figure: 3 Registration Page

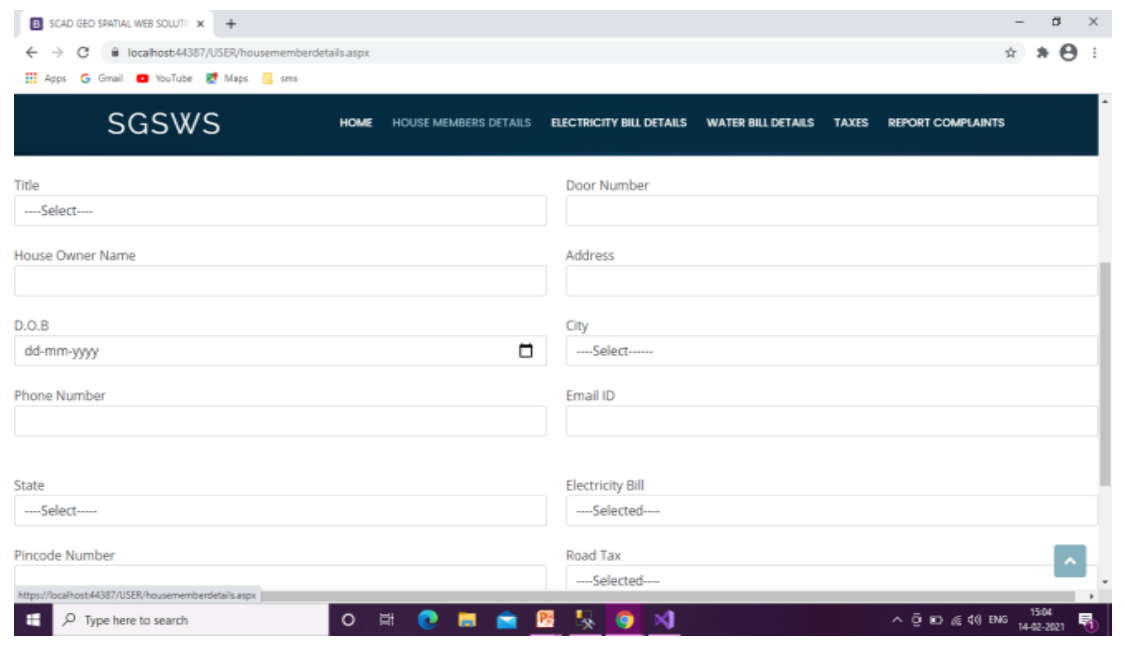

Figure: 4 House Member Details

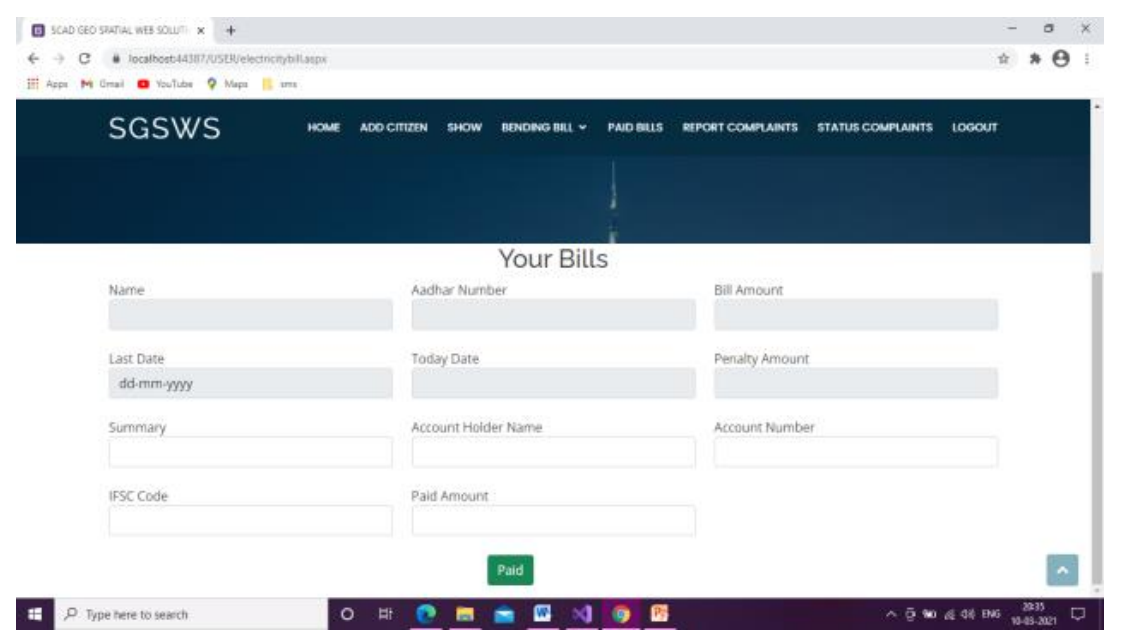

Figure: 5 Bill Payment 

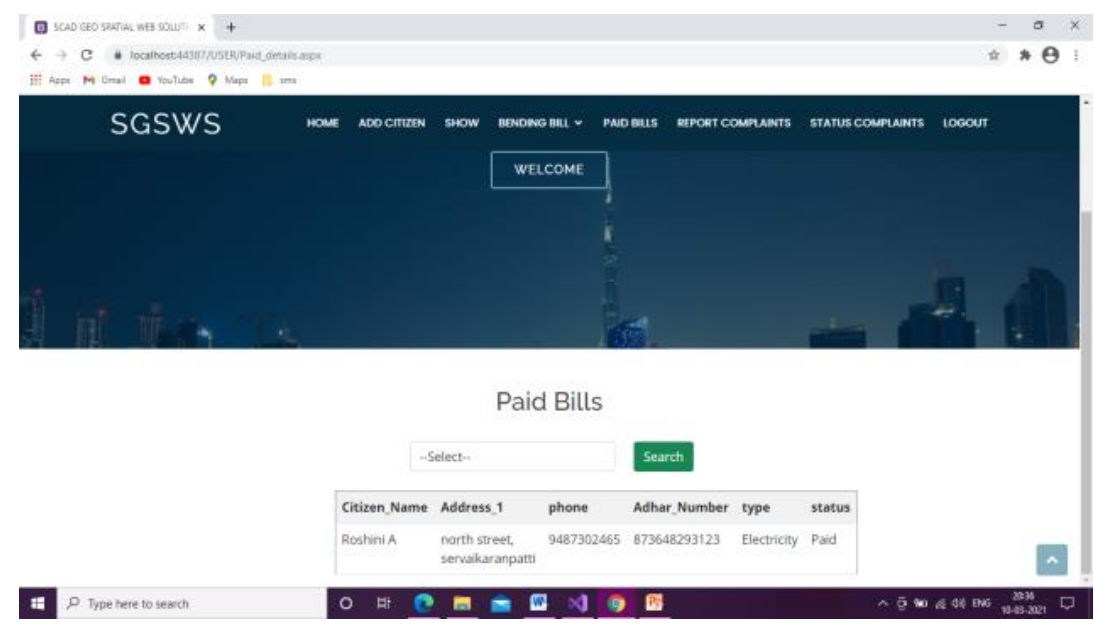

Figure: 6 Paid Bills

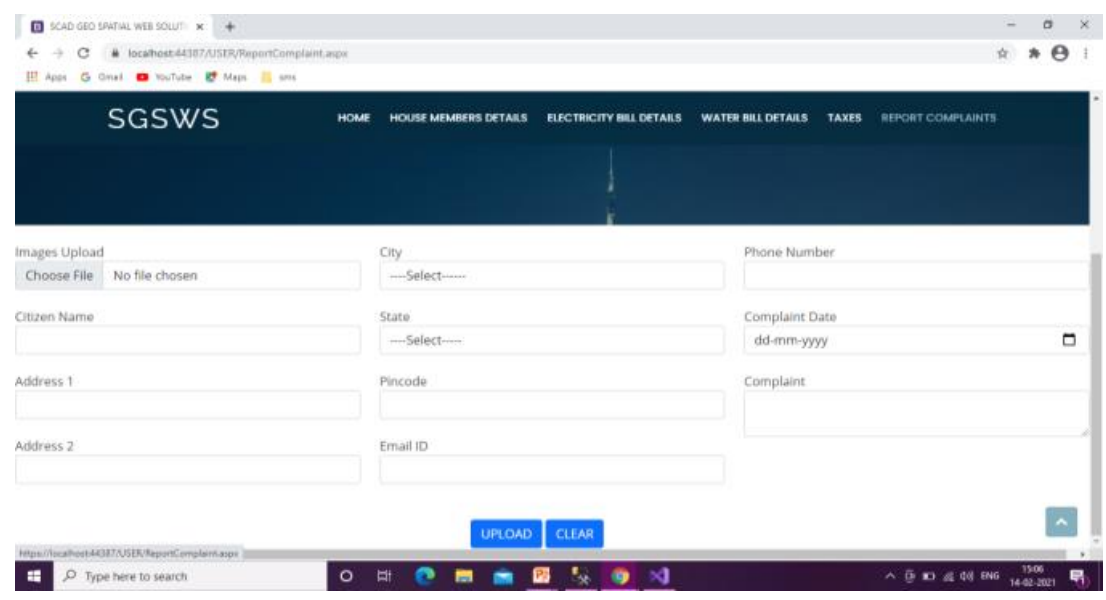

Figure: 7 Report Complaints

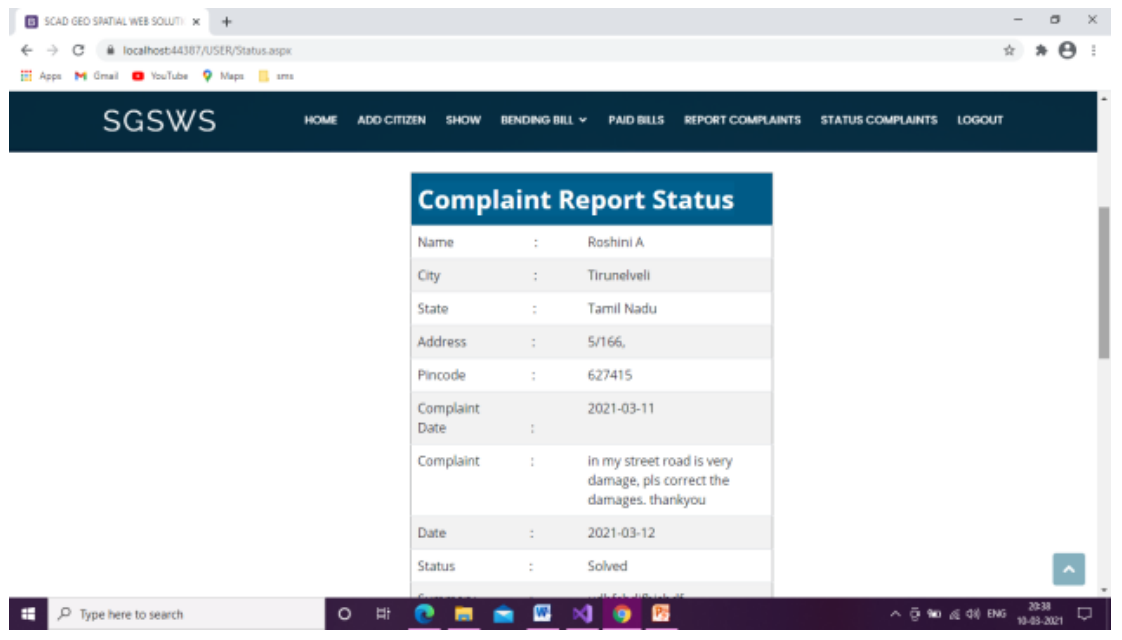

Figure: 8 Report Complaints 


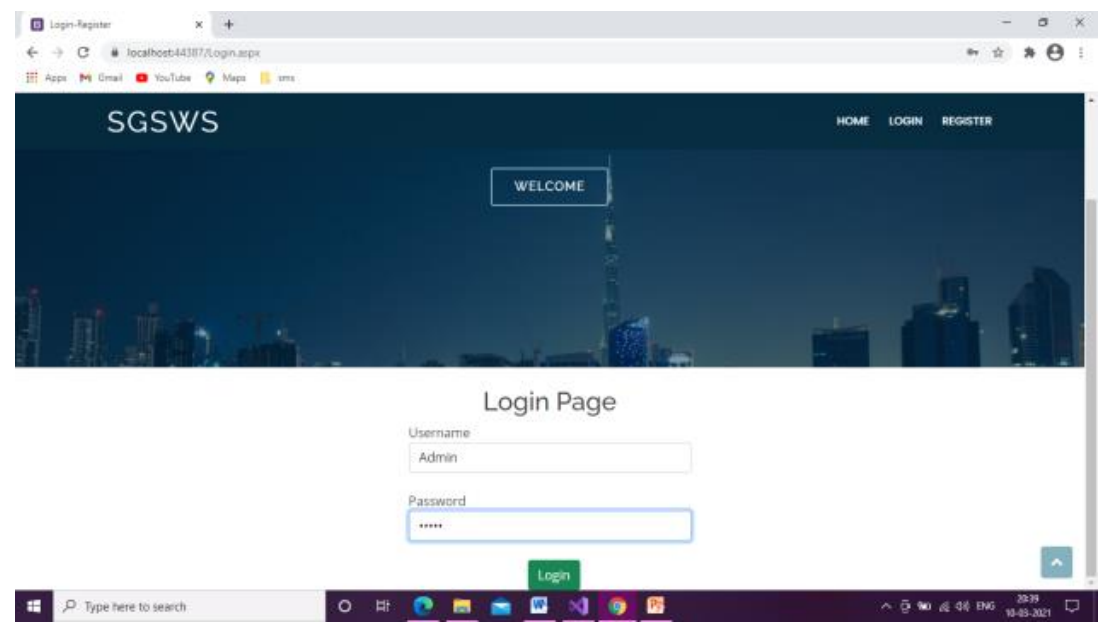

Figure: 9 Admin Login Page
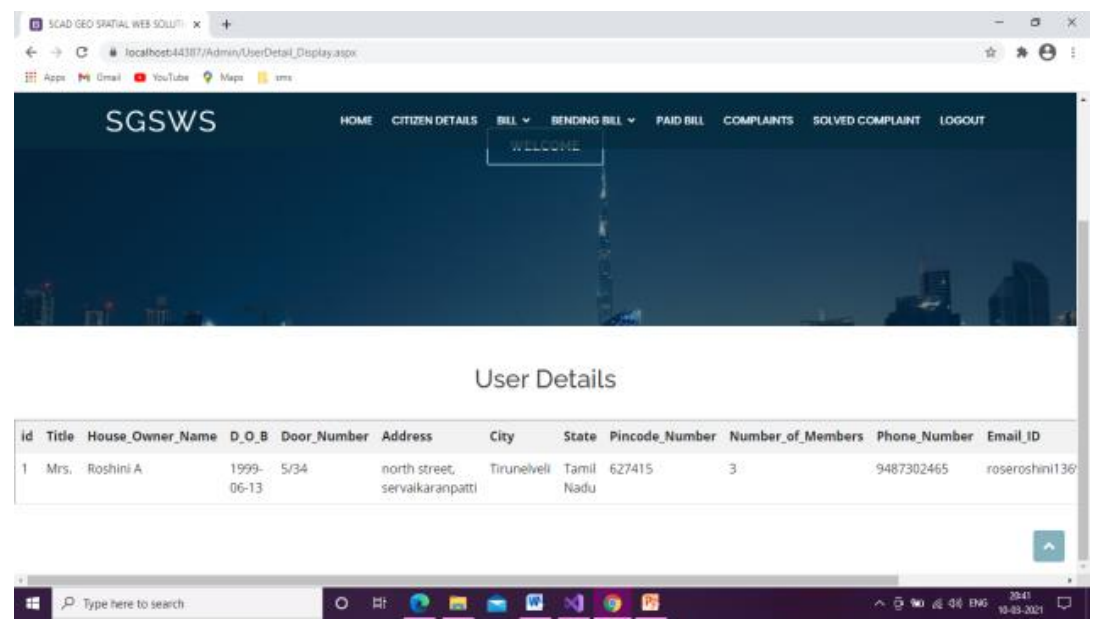

Figure: 10 Citizen's Details

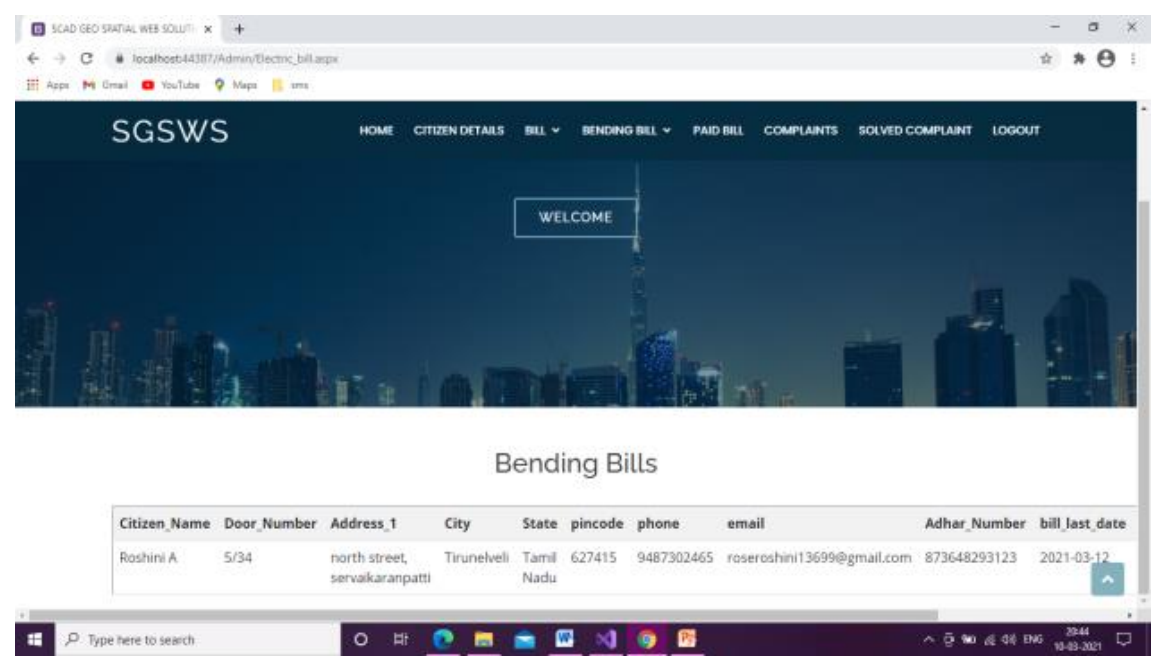

Figure: 11 Bills 


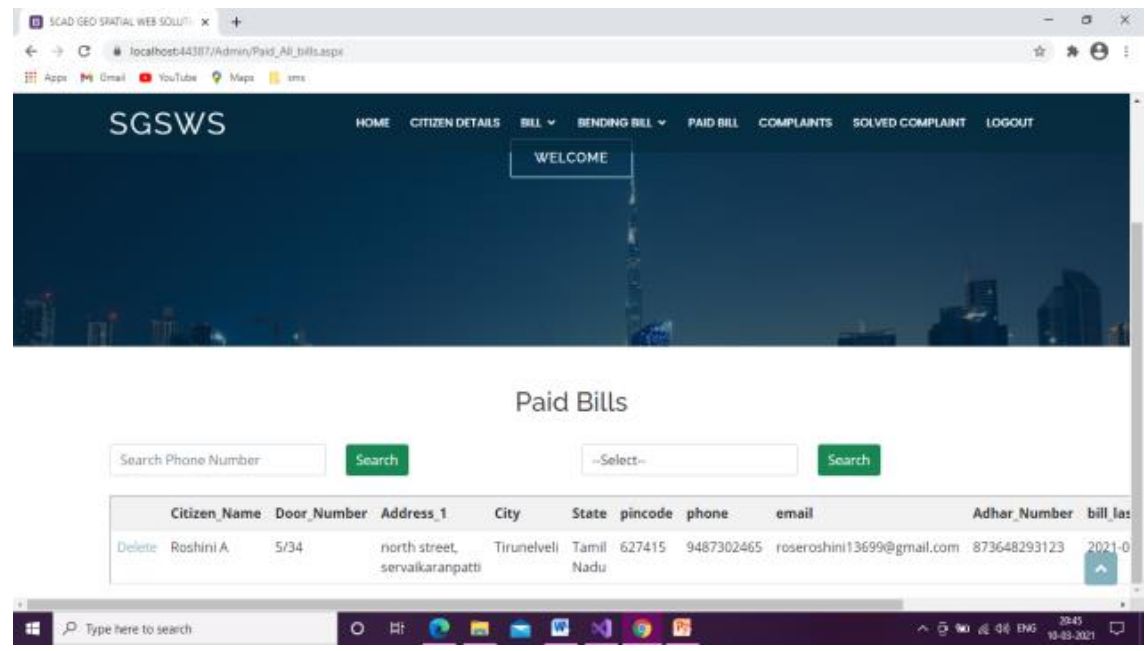

Figure: 12 Bending Bills
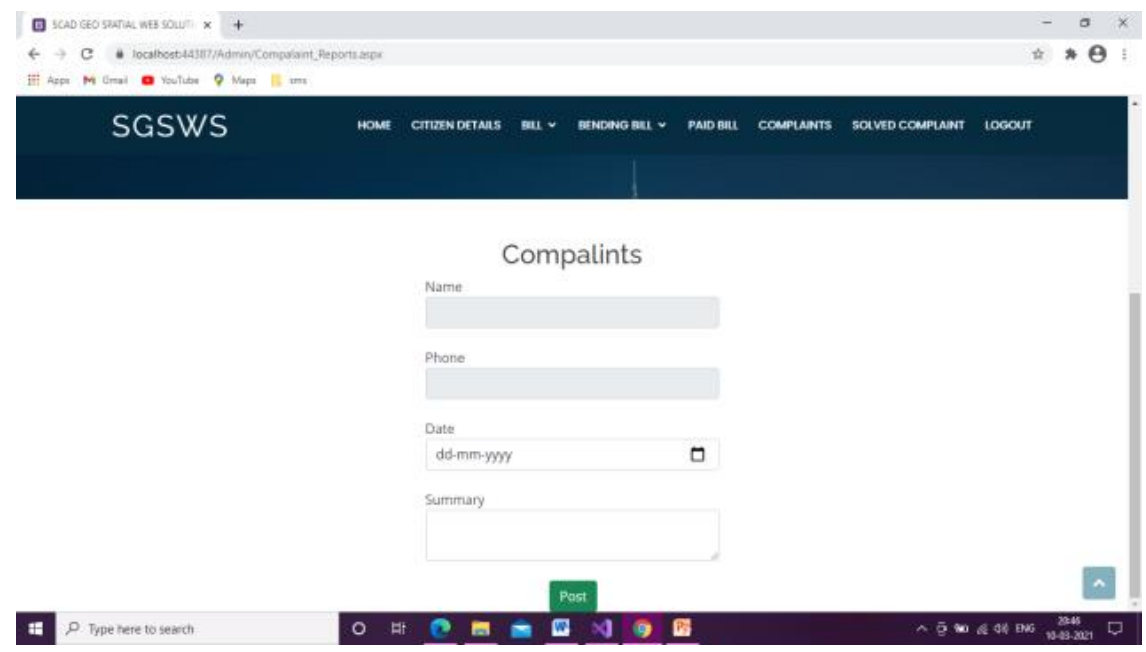

Figure: 13 Paid Bills

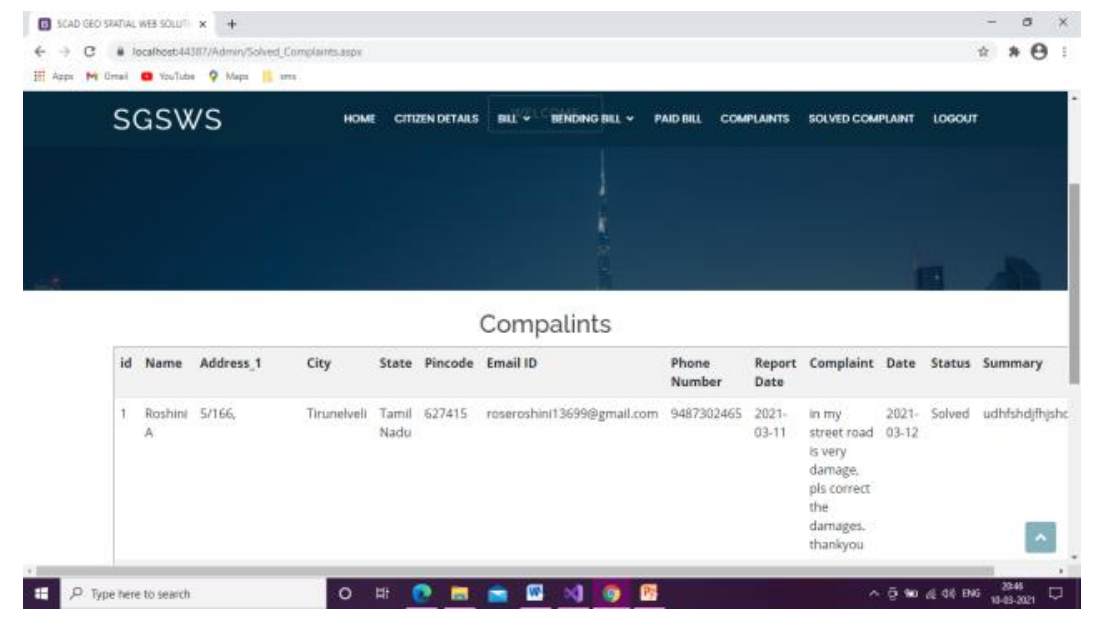

Figure: 14 Complaint Actions 


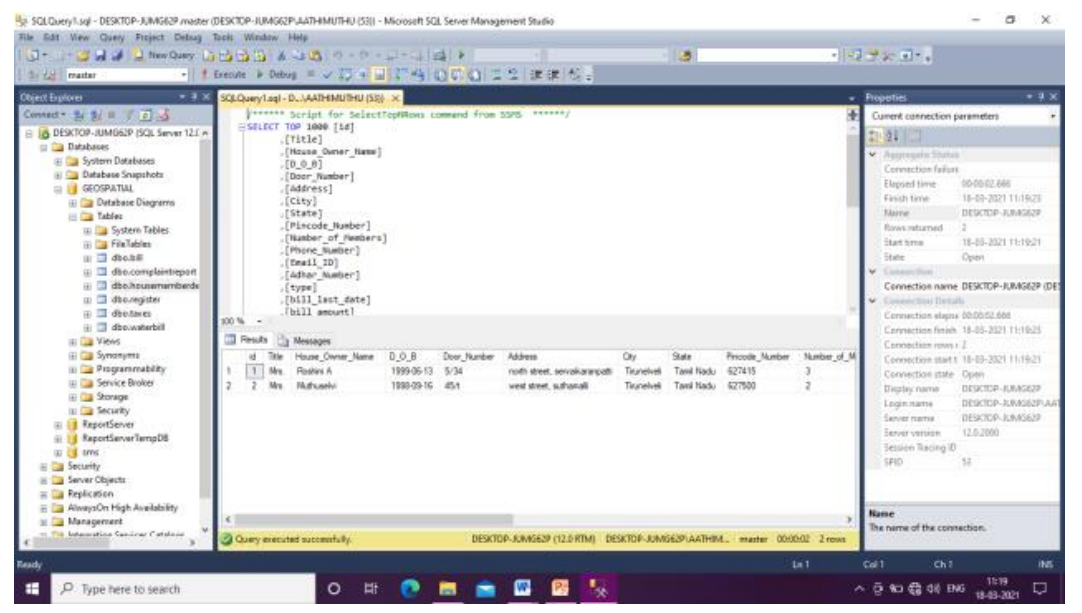

Figure: 15 Solved Complaints

\section{Performance AnAlysis}

The existing and proposed systems are analyzed. The problems can be easily rectified with this concept. Nearly $70 \%$ of the performance has been increased.

\section{CONCLuSiON}

It has been a great pleasure for me to work on this exciting and challenging project. This project proved good for me as it provided practical knowledge of not only programming in ASP.NET andC\#.NET web based application and no some extent Windows. It also provides knowledge about the latest technology used in developing web enabled application and client server technology that will be great demand in future. This will provide better opportunities and guidance in future in developing projects independently.

\section{FUTURE ENHANCEMENT}

This System being web-based and an undertaking of Cyber Security Division, needs to be thoroughly tested to find out any security gaps. A console for the data centre may be made available to allow the personnel to monitor on the sites which were cleared for hosting during a particular period. Moreover, it is just a beginning; further the system may be utilized in various other types of auditing operation viz. Network auditing or similar process/workflow based applications.

\section{REFERENCES}

[1] PimpriChinchwad Municipal Corporation, "SMS and Web-Based Complaint Monitoring System," Viewed Jul.2012;http://www.asci.org.in/ICT/Resources/CaseStudies/CITIZENCENTRIC/32SMS\%20\&\%20 Web\%20based\%20Complaint\%20Monitoring\%20System\%20Pimpri\%20Chinchwad.PDF

[2] e-scrap news, Special Report, Feb. 2004.

[3] The National Safety Council, "Electronic Product Recovery and Recycling Baseline Report: Recycling of Selected Electronic Products in the United States," 1999. 
[4] Communications with Goodwill Industries of Central Texas, 2004 and 2005.

[5] S. Kucuk, F. Arslan, M. Bayrak, G. Contreras, Load management of industrial facilities electrical system using intelligent supervision, control and monitoring systems, in: International Symposium on Networks, Computers and Communications (ISNCC), 2016.

[6] Afify, E., Hegazy, A., \& El-Sayed, M., (2011). "A Model For Customer Complaint Management System using SOA. ", In Proceedings of the 15th WSEAS International Conference on Computers, World Scientific and Engineering Academy and Society (WSEAS), 291-296.

[7] Liu, L.; Li, B.; Zlatanova, S.; Liu, H. The Path from Bim to a 3d Indoor Framework-A Requirement Analysis. Int. Arch. Photogramm. Remote Sens. Spat. Inf. Sci. 2018, XLII-4, 373-378.

[8] Sirdeshmukh, N.; Verbree, E.; Oosterom, P.V.; Psomadaki, S.; Kodde, M. Utilizing a Discrete Global Grid System for Handling Point Clouds with Varying Locations, Times, and Levels of Detail. Cartographica: Int. J. Geogr. Inf. Geovis. 2019, 54, 4-15.

[9] Breunig, M.; Kuper, P.V.; Butwilowski, E.; Thomsen, A.; Jahn, M.; Dittrich, A.; Al-Doori, M.; Golovko, D.; Menninghaus, M. The story of DB4GeO-A service-based geo-database architecture to support multi-dimensional data analysis and visualization. ISPRS J. Photogramm. Remote Sens. 2016, 117, 187-205.

[10] Kuper, P.V. Efficient and Practical Handling of Spatio-Temporal Data Based on Time-Dependent Net Components. Int. Arch. Photogramm. Remote Sens. Spat. Inf. Sci. 2018, XLII-4, 321-327. 


\section{AuTHORS}

Ms.A.Roshini doing final year MCA in Francis Xavier Engineering College.

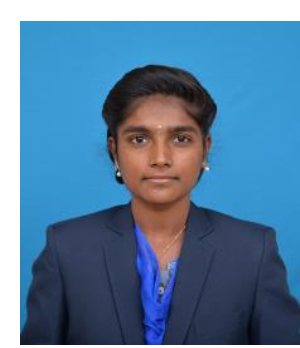

Mrs. D. Angeline Ranjithamani is working as Assistant Professor and HOD in the Department of Computer Applications, Francis Xavier Engineering College. She is having teaching experience of $12+$ years. Her area of interest is Wireless Sensor networks.

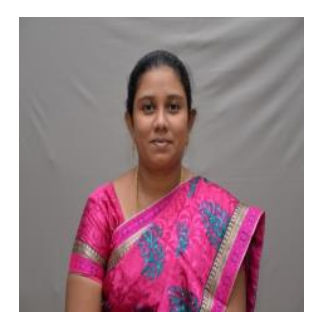

Ms.C.Deepa doing first year MCA in Francis Xavier Engineering College.

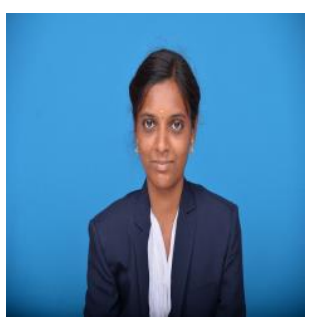

